Proc. Indian Acad. Sci. (Chem. Sci.), Vol. 108, No. 5, October 1996, pp. 459-468.

(C) Printed in India.

\title{
Analysis of geometric and strain effects in homo-Diels-Alder reactions
}

\begin{abstract}
ANIMESH PRAMANIK and JAYARAMAN CHANDRASEKHAR*
Department of Organic Chemistry, Indian Institute of Science, Bangalore 560012, India

MS received 12 August 1996

Abstract. Molecular mechanics calculations have been carried out to quantify the key geometric and strain effects which are likely to control the homo-Diels-Alder reactivity of 1,4-dienes. The criteria considered include $\mathrm{C} 1$. . C5 and C2 . C4 distances in the diene, twist angle of the two $\pi$ units, and the magnitude of strain increase as a result of cycloaddition. By first considering these factors in a number of nonconjugated dienes with known reactivity, the ranges of values within which the reaction is favoured are proposed. Calculations are also reported on several substrates which have not been investigated so far. Promising systems for experimental study are suggested which, in addition to being intrinsically interesting, would place the present proposals on a firm basis.
\end{abstract}

Keywords. Homo-Diels-Alder reaction; molecular mechanics; strain; modelling.

\section{Introduction}

The homo-Diels-Alder (HDA) reaction involving a non-conjugated 1,4-diene and a dienophile is a potentially useful method for the synthesis of bridged polycyclic compounds, producing two $\mathrm{C}-\mathrm{C} \sigma$ bonds and a cyclopropane ring in one step (scheme 1). The reaction, known for over 3 decades (Ullman 1958; Blomquist and Meinwald 1959; Hall 1960; Cristol et al 1962; Cookson and Dance 1962; Moriarty 1963; Cookson et al 1964; Schrauzer and Glockner 1964; Huebner et al 1966; Tufariello et al 1966; Sasaki et al 1972), represents a specific example of a more general class of $[2+2+2]$ cycloadditions. However, compared to the Diels-Alder reaction, the mechanistic details of the HDA reaction are less understood and the methodology is underexploited in organic synthesis.

The reaction is generally thought of as a sluggish process lacking stereo-electronic control. The reactants involve non-conjugated species and hence are not amenable to electronic activation. While stereospecificity and concerted pathways have indeed been proposed in certain cases (Kobuke et al 1972; Tabushi et al 1975; Jenner and Papadopoulos 1982), and regioselectivity in cobalt-catalyzed reactions (Lautens and Edwards 1991), the reaction in general is likely to involve biradicaloid intermediates. The factors which determine HDA reactivity are therefore likely to be purely geometric in nature.

The first systematic investigation of the scope of the HDA reaction involving various dienes with a common reactive dienophile confirmed the above view (Fickes and Metz 1978). The ease of reaction of $\underline{1}-\underline{7}$ with tetracyanoethylene (TCNE) was suggested to be

*For correspondence 


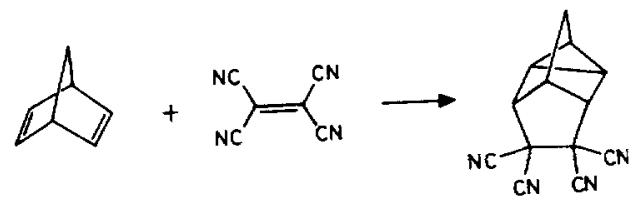

Scheme 1. Representative homo-Diels-Alder reaction.

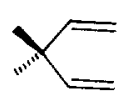

1

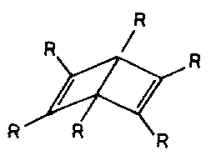

$\underline{5 a}: \mathrm{R}=\mathrm{CH}_{3}$

$5 \mathrm{~b}: \mathrm{R}=\mathrm{H}$

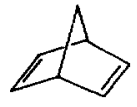

$\underline{2}$

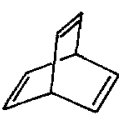

$\underline{6}$

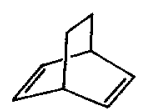

$\underline{3}$

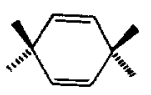

$\underline{7}$

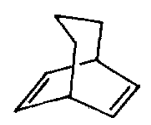

$\leq$

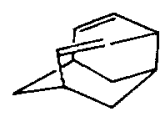

$\underline{8}$

inversely related to the distance between the double bonds estimated from models. Only two exceptions were noted. The unreactive nature of acyclic 1 was attributed to the unfavourable entropic term. For $\underline{Z}$, estimates of strain energies indicated that the formation of a three-membered ring is highly unfavourable.

The presence of an additional factor controlling HDA reactivity was revealed by the facile reaction of tricyclo $\left[5 \cdot 3 \cdot 1 \cdot 0^{4,9}\right]$ undeca-2,5-diene, $\underline{8}$ with TCNE (Yamaguchi et al 1984). Both MM2 and $a b$ initio (STO-3G) calculations indicated a fairly large separation between the reactive sites of the diene $(\approx 3 \cdot 4 \AA)$. The remarkable reactivity of $\underline{8}$ was explained on the basis of the mutual orientation of the $\pi$ bonds. The $\pi$ lobes are directed towards each other allowing for strong through-space interactions. The orbital tilt is also ideally suited for maximising overlap with an approaching dienophile. It was concluded that close proximity of the double bonds is not a prerequisite for significant HDA reactivity.

In this paper, we attempt to place geometric and strain factors which determine the feasibility of HDA reaction on a quantitative basis. Molecular mechanics calculations have been used for this purpose. First, several dienes which have been experimentally examined are considered. After obtaining general criteria for HDA reactivity, additional systems not yet experimentally studied are evaluated. Suitable substrates for further investigation to quantify our proposals are suggested.

\section{Results and discussion}

\subsection{Computational model}

Geometry optimisation using the MM2 force field (Allinger 1977) was carried out on a number of non-conjugated dienes. The reactivity of the dienes towards TNCE or related activated dienophiles was correlated with specific structural parameters. Among the various possible factors which can influence HDA reactivity, the $\mathrm{C}_{1} . . \mathrm{C}_{5}$ and $\mathrm{C}_{2} . . \mathrm{C}_{4}$ distances of the 1,4-diene (figure 1a) are important. Shorter distances will 
(a)

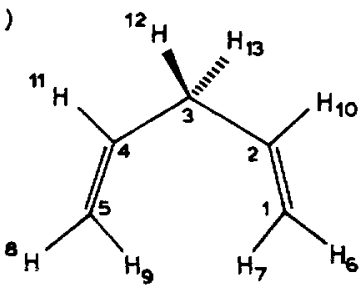

(b)

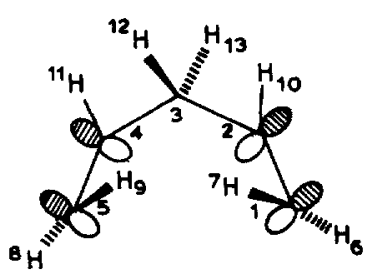

Figure 1.(a) Atom numbering for a representative 1,4-diene used in the definition of geometrical parameters in the text. (b) Twist at the terminal carbon atoms which would favour stabilising orbital interactions with an approaching dienophile.

enhance through-space interactions between the double bonds. Further, the terminal carbon atoms of the diene would be ideally poised for interaction with the approaching dienophile, while the internal carbon atoms can form a new $\mathrm{C}-\mathrm{C}$ bond more readily.

The mutual alignment of the double bonds is also a key factor which determines through-space interactions and the ability to interact with a dienophile. The relative orientations of the $\pi$ lobes of a double bond at each carbon centre can be quantified by two dihedral angles, viz., the inner tilt angle and the outer tilt angle, which we define as follows (figure 1a). At the terminal carbon atoms (at $C_{1}$ and $C_{5}$ ), the inner tilt angles $\left(\Phi_{1 \mathrm{i}}\right)$ are the dihedral angles $\mathrm{H}_{7} \mathrm{C}_{1} \mathrm{C}_{2} \mathrm{C}_{4}$ and $\mathrm{H}_{9} \mathrm{C}_{5} \mathrm{C}_{4} \mathrm{C}_{2}$. For a symmetrical diene the absolute values of these two dihedral angles are equal. Similarly the outer tilt angles $\left(\Phi_{1 \mathrm{o}}\right)$ are chosen as the dihedral angles $\mathrm{H}_{6} \mathrm{C}_{1} \mathrm{C}_{2} \mathrm{C}_{4}$ and $\mathrm{H}_{8} \mathrm{C}_{5} \mathrm{C}_{4} \mathrm{C}_{2}$, whose absolute values are again equal for a symmetrical diene. When the $\pi$ lobes at the terminal carbon atoms (at $\mathrm{C}_{1}$ and $\mathrm{C}_{5}$ ) of the diene are parallel to each other and have the least direct overlap, the inner tilt angles are zero and the outer tilt angles are $180^{\circ}$. As the inner tilt angle increases and the outer tilt angle correspondingly decreases, the $p$-lobes of the double bonds at the terminal carbon atoms are twisted towards each other (see figure $1 b$ ). This is favourable for HDA reactivity because the diene can interact strongly with the approaching dienophile.

The $C_{1}-C_{2}$ and $C_{4}-C_{5}$ bonds are not necessarily parallel in most 1,4-dienes. In typical unsymmetrical structures, intramolecular through-space interactions involving the internal carbon atoms $\mathrm{C}_{2}$ and $\mathrm{C}_{4}$ will be larger than those involving the terminal atoms $\mathrm{C}_{1}$ and $C_{5}$. Therefore, it is important to consider the mutual orientation of the $p(\pi)$-lobes at $C_{2}$ and $\mathrm{C}_{4}$ also. The relative alignment can be quantified by the inner and outer tilt angles in a way similar to that done in the case of terminal carbon atoms. Thus, the inner tilt angles $\left(\Phi_{2 \mathrm{i}}\right)$ are $\mathrm{C}_{3} \mathrm{C}_{2} \mathrm{C}_{1} \mathrm{C}_{5}$ and $\mathrm{C}_{3} \mathrm{C}_{4} \mathrm{C}_{5} \mathrm{C}_{1}$ dihedral angles, while the outer tilt angles $\left(\Phi_{2 \mathrm{o}}\right)$ are $\mathrm{H}_{10} \mathrm{C}_{2} \mathrm{C}_{1} \mathrm{C}_{5}$ and $\mathrm{H}_{11} \mathrm{C}_{4} \mathrm{C}_{5} \mathrm{C}_{1}$ torsion angles. For a symmetrical diene, such as 2 , the absolute values of both the inner tilt angles as well as the outer tilt angles are equal. The through-space interaction between the $p$-lobes at the internal carbon atoms is maximum if the inner and outer tilt angles are $-90^{\circ}$ and $90^{\circ}$ respectively.

Since a cyclopropyl ring is formed in the HDA reaction, strain effects also need to be assessed. Molecular mechanics provides a sound basis for studying such effects. The increase in strain energy on going from the diene to the HDA adduct using ethylene as a model dienophile $\left(\Delta E_{\text {strain }}\right)$ has been calculated for various 1,4 -dienes.

The calculated distances, tilt angles and strain energy changes for cycloadduct formation for $1-\underline{7}$ are given in table 1 . The data provide a quantitative basis for evaluating the reactivity of the dienes with a common dienophile. For a direct 
Table 1. MM2 geometric parameters and the increase in strain energy $\left(\Delta E_{\text {strain }}\right)$ on going from the diene to the homo-Diels-Alder adduct for various 1,4-dienes.

Bond lengths in $\AA$; angles in degrees; strain energy in $\mathrm{kcal} / \mathrm{mol}$.

\begin{tabular}{|c|c|c|c|c|c|c|c|}
\hline $\begin{array}{l}1,4- \\
\text { Diene }\end{array}$ & $\begin{array}{c}\mathrm{C}_{1} \ldots \mathrm{C}_{5} \\
(\AA)\end{array}$ & $\begin{array}{c}C_{2} \ldots C_{4} \\
(\AA)\end{array}$ & $\Phi_{1 i}$ & $\Phi_{10}$ & $\Phi_{2 i}$ & $\Phi_{20}$ & $\Delta E_{\text {strain }}$ \\
\hline$\frac{\frac{1}{2}}{\frac{2}{4}} \frac{\frac{5}{5 a}}{\frac{5 b}{6}}$ & $\begin{array}{l}3 \cdot 41 \\
2 \cdot 40 \\
2 \cdot 39 \\
2 \cdot 41 \\
2 \cdot 58 \\
2 \cdot 60 \\
2 \cdot 38 \\
2 \cdot 51 \\
3 \cdot 46\end{array}$ & $\begin{array}{l}2 \cdot 45 \\
2 \cdot 40 \\
2 \cdot 39 \\
2 \cdot 41 \\
2 \cdot 58 \\
2 \cdot 60 \\
2 \cdot 38 \\
2 \cdot 51 \\
2 \cdot 31\end{array}$ & $\begin{array}{l}38 \\
33 \\
29 \\
24 \\
30 \\
30 \\
30 \\
1 \\
51\end{array}$ & $\begin{array}{l}-141 \\
-145 \\
-151 \\
-156 \\
-148 \\
-149 \\
-149 \\
-179 \\
-130\end{array}$ & $\begin{array}{l}-37 \\
-33 \\
-29 \\
-24 \\
-30 \\
-30 \\
-30 \\
-1 \\
-45\end{array}$ & $\begin{array}{l}141 \\
145 \\
151 \\
156 \\
148 \\
149 \\
149 \\
179 \\
130\end{array}$ & $\begin{array}{l}30 \cdot 2 \\
21 \cdot 3 \\
31 \cdot 9 \\
43 \cdot 6 \\
30 \cdot 5 \\
34 \cdot 2 \\
24 \cdot 0 \\
46 \cdot 5 \\
31 \cdot 5\end{array}$ \\
\hline
\end{tabular}

assessment, a summary of available experimental information on HDA reactions involving these dienes is provided in table 2 (Blomquist and Meinwald 1959; Krespan et al 1961; Zimmerman and Swenton 1964; Grant et al 1965; Sasaki et al 1972; Iwamura et al 1976; Fickes and Metz 1978; Yamaguchi et al 1984b). Since the experimental studies have been carried out under different conditions, the data are used only to make a qualitative judgement of the ease of homo-Diels-Alder reaction of the various substrates.

\subsection{Analysis of systems with known reactivity}

The calculated results in table 1 are of considerable interpretive value. The data have a more quantitative basis than the previous analysis (Fickes and Metz 1978) using Dreiding models. Interestingly, among the bicyclic dienes $\underline{2}-\underline{4}$, the variation in the $\mathrm{C}_{1} . . \mathrm{C}_{5}$ distance is not as large as had been suggested by these authors. Hence, the importance of this factor in these dienes had been overemphasized. On the basis of MM2 calculations, the geometric factors are quite similar in these dienes. The key difference is found in the strain energy increase on HDA addition. While the increase is only $21 \mathrm{kcal} / \mathrm{mol}$ for norbornadiene, it becomes progressively larger, by over $10 \mathrm{kcal} / \mathrm{mol}$, for the bicyclooctadiene (3) and the bicyclononadiene (4) derivatives. Therefore, the rapid fall in the HDA reactivity of these dienes with TCNE may be understood on the basis of the strain factor alone. The geometric and strain factors computed for the Dewar benzenes $(\underline{5 \mathrm{a}, \mathrm{b}})$ and barrelene (6) are also within the acceptable range for facile homo-Diels-Alder reaction.

As pointed out earlier (Yamaguchi et al 1984b), the reactivity of the tricyclic diene $\underline{8}$ can be understood in terms of the significant tilt of the $\pi$ lobes towards each other. The data in table 1 provide a useful comparison. Among the various dienes shown in table 1 , the inner tilt at the terminal carbon atom is the largest $\left(51^{\circ}\right)$ for $\underline{8}$. The inner tilt at the internal carbon atom is also quite large $\left(-45^{\circ}\right)$ to produce strong through-space interactions between the double bonds. The strain energy increase, although larger than in $\underline{2}$, is comparable to that obtained for the relatively reactive diene $\underline{\underline{3}}$. These favourable factors enable the diene to be reactive towards TCNE in spite of a relatively large separation of $3.46 \AA$ between the terminal olefinic carbon atoms. 
Table 2. Reaction conditions and yields for the homo-Diels-Alder reactions of several 1,4-dienes with various dienophiles.

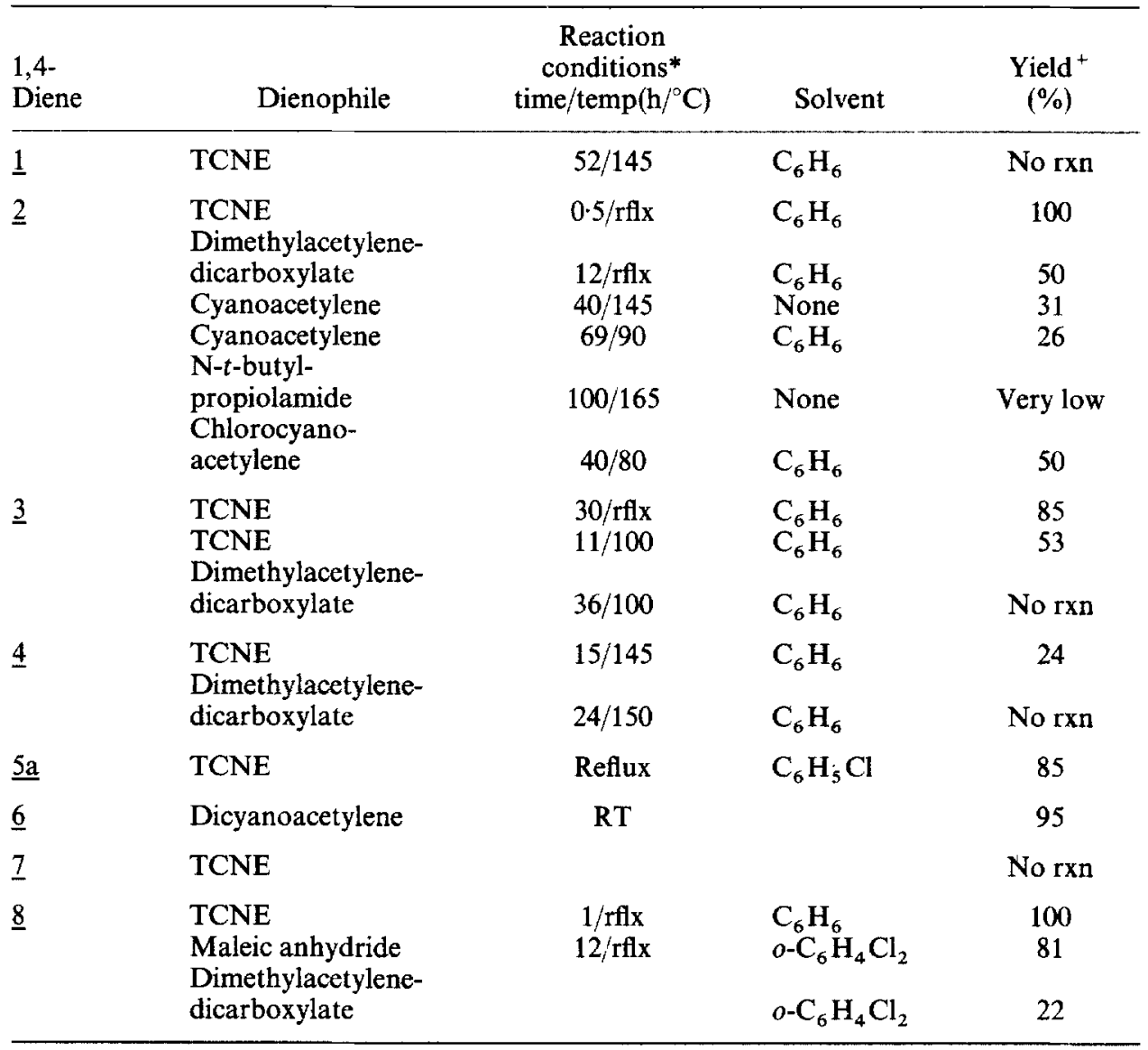

"rflx = reflux; + "No rxn" indicates "no reaction"

It is known that 3,3-dimethyl-1,4-pentadiene ( $\underline{1})$ and 3,3,6,6-tetramethyl-1,4-cyclohexadiene ( 7 ) do not undergo the HDA reaction even with the highly activated dienophile TCNE (table 2). MM2 calculation shows that 3,3-dimethyl-1,4-pentadiene has a $C_{1} \ldots C_{5}$ distance of $3.41 \AA$ and a strain energy increase of $30 \mathrm{kcal} / \mathrm{mol}$. These values are comparable to those obtained for the reactive diene $\underline{8}$. The tilt angles at the terminal carbon atoms $\left(38^{\circ}\right.$ and $\left.-148^{\circ}\right)$ as well as at the internal carbon atoms $\left(-37^{\circ}\right.$ and $\left.141^{\circ}\right)$ also suggest reasonable mutual alignment of the $\pi$ lobes for favourable overlap. Therefore the failure of 1 to undergo the HDA reaction with TCNE may be due to the entropic factor, as suggested before (Fickes and Metz 1978). In the case of $I$, only the distance criterion for efficient HDA reaction is met (table 1). The ground state geometry of the diene is planar at the MM2 level, in agreement with $a b$ initio calculations (Birch et al 1981). Hence the absence of any tilt of the double bonds precludes significant through-space interactions. The unfavourable strain effect postulated earlier (Fickes and Metz 1978) on the basis of rates of model reactions is also confirmed by the present calculations. The increase in strain following addition to $\underline{Z}$ is 
greater than $46 \mathrm{kcal} / \mathrm{mol}$. The non-reactivity of this diene with TCNE is consistent with the MM2 results.

On the basis of the above comparison of calculated parameters and experimental results, a set of guidelines can be proposed for predicting the HDA reactivity of a non-conjugate diene. The $\mathrm{C}_{2} . . \mathrm{C}_{4}$ distance is relatively unimportant. Dienes with a $C_{1} \ldots C_{5}$ separation of even $3.5 \AA$ can be reactive provided there is sufficient tilt of the $\pi$ lobes at the internal and terminal carbon atoms. The increase in strain following addition should not exceed $40 \mathrm{kcal} / \mathrm{mol}$.

The above criteria were tested against the known reactivity pattern of $1,3,5,7$ tetramethylenecyclooctane ( $(\underline{9})$ towards dienophiles. In principle, the molecule $\underline{9}$ can undergo a homo-Diels-Alder type addition to give 10 or a $2+2+2$ cycloaddition involving the exocyclic double bonds at $\mathrm{C} 1$ and $\mathrm{C} 5$ to yield 11 (scheme 2). Experimentally, only the latter mode of cycloaddition is observed (Williams and Benson 1962). This can be rationalised on the basis of geometric and strain considerations.

Three conformations are reasonable for 9 (figure 2 ). In the $D_{2 d}$ form $\underline{9 a}$, the exocyclic double bonds at $\mathrm{C} 1$ and $\mathrm{C} 5$ are oriented ideally for interaction with an approaching dienophile. In contrast, the geometry of the $C_{2 h}$ conformer, $\underline{9 b}$, permits only a homoDiels-Alder type cycloaddition. Both cycloaddition modes are possible, in principle, for conformer $9 \mathrm{c}$ with $C_{4 v}$ symmetry. All three forms were optimised at the MM2 level. Strain energy changes for cycloaddition to ethylene were also computed.

The requirements for homo-Diels-Alder reaction are fairly met in conformer $\underline{9 b}$ (table 3 ). The terminal carbon atoms are separated by $3.4 \AA$, while the internal carbon atoms are $2.5 \AA$ apart. The $\pi$ bonds are partially tilted towards each other and the strain energy increase for cycloaddition is modest (table 3 ). However, this conformer is the least stable of the three considered $\left(\Delta H_{f}=52.5 \mathrm{kcal} / \mathrm{mol}\right)$.

The homo-Diels-Alder mode should be favoured in the more stable form $\underline{9 c}$ also $\left(\Delta H_{f}=48.6 \mathrm{kcal} / \mathrm{mol}\right)$, although the criteria are slightly less favourable than in $9 \mathrm{~b}$ (table 3). The double bonds at $\mathrm{C} 1$ and $\mathrm{C} 5$ are too widely separated (terminal distance $=5 \cdot 1 \AA$, internal distance $=3 \cdot 5 \AA$ ) to favour the formation of 11 .

The preferred formation of 11 is supported by the geometry and strain of the most stable conformation $\underline{9 \mathrm{a}}\left(\Delta H_{f}=45.9 \mathrm{kcal} / \mathrm{mol}\right)$. The terminal carbon atoms of the reactive ends of $9 \mathrm{a}$ have the least separation of the three conformers considered $(3 \cdot 17 \AA$ ), while the internal carbon atoms are also quite close, $2.79 \AA$ (table 3). Further,

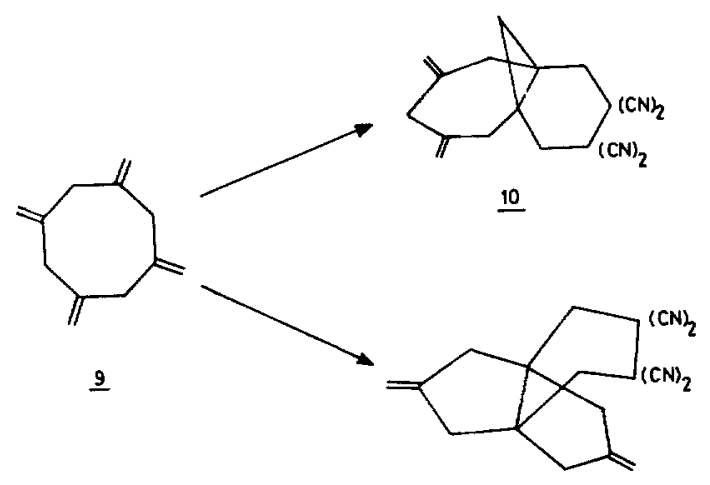

11

Scheme 2. Possible cycloaddition modes of 9 with TCNE 


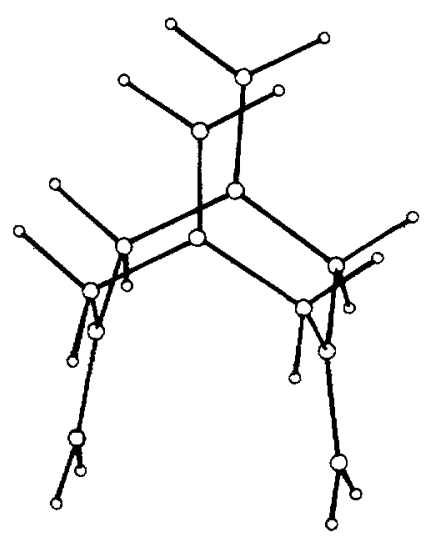

$\underline{9 a}\left(D_{2 d}\right)$

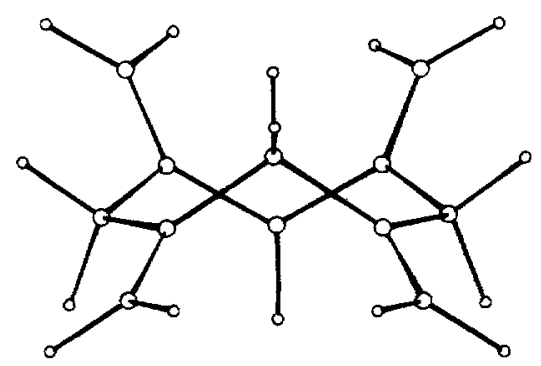

$\underline{90}\left(C_{2 n}\right)$

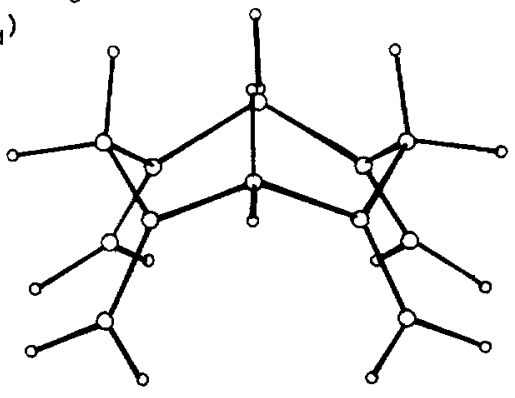

$\underline{9 c}\left(C_{4 V}\right)$

Figure 2. Three optimised conformations of tetraene 2.

Table 3. MM2 geometric parameters and the increase in strain energy ( $\left.\Delta E_{\text {strain }}\right)$ for cycloadduct formation for various conformations of $\underline{9}$.

$r$ in $\AA$; angles in degrees; strain energy in $\mathrm{kcal} / \mathrm{mol}$.

\begin{tabular}{lccccccc}
\hline Conformer & $r_{\text {term }}$ & $r_{\text {inner }}$ & $\Phi_{1 i}$ & $\Phi_{1 o}$ & $\Phi_{2 i}$ & $\Phi_{2 o}$ & $\Delta E_{\text {strain }}$ \\
\hline$\underline{9 \mathrm{a}}$ & 3.17 & 2.79 & 90 & -90 & -90 & 90 & 17.0 \\
$\underline{9 \mathrm{~b}}$ & 3.40 & 2.51 & 34 & -145 & -34 & 145 & 21.9 \\
$\underline{9 \mathrm{c}}$ & 3.59 & 2.48 & 39 & -140 & -39 & 140 & 23.2 \\
\hline
\end{tabular}

the $\pi$ bonds are favourably oriented towards each other (figure 2). Most importantly, the $2+2+2$ cycloaddition reaction does not lead to the formation of a 3-membered ring, but to a less strained 5-membered ring. The overall strain energy increase on cycloaddition is just $17.0 \mathrm{kcal} / \mathrm{mol}$. Thus, all geometric and strain energy criteria clearly favour this mode of reaction.

\subsection{Predictions for new substrates}

It would be of considerable interest to critically evaluate the above proposals with additional dienes. In particular, the outer limits for the distance criterion and the strain factor need to be evaluated. With these goals in mind, we have computed the geometric 
and energetic factors of importance in HDA reactivity for a number of non-conjugated dienes which have not been studied experimentally. After an analysis, the systems ideally suited for further study which would enable a quantitative definition of the scope of the HDA reaction are identified.

Two series of 1,4-dienes have been considered. The first is a set of bicyclo [3.3.n] dienes $(\underline{12}-15)$. These are clearly related to the bicyclic dienes $\underline{2}-6$ which have been studied extensively. The second is a set of relatively rigid molecules $(\underline{16}-\underline{21})$ in which the terminal units of the diene are geometrically capable of responding flexibly to a dienophile. In our terminology, the inner and the outer tilt angles at the terminal carbon atoms are not constrained by the ring skeletons in these systems. The calculated MM2 geometric parameters of interest and the increase in strain energy due to HDA addition for the two series of compounds are provided in table 4 .

The MM2 results in table 4 show that the series of bicyclo $[3 \cdot 3 \cdot n]$ dienes (12-15) have $\mathrm{C}_{1} . . \mathrm{C}_{5}$ distances of $3.5 \AA$ or more. The values are significantly larger compared to those

Table 4. MM2 geometric parameters and the increase in strain energy $\left(\Delta E_{\text {strain }}\right)$ on going from the diene to the homo-Diels-Alder adduct for additional 1,4-dienes.

Bond lengths in $\AA$; angles in degrees; strain energy in kcal $/ \mathrm{mol}$

\begin{tabular}{|c|c|c|c|c|c|c|c|}
\hline $\begin{array}{l}1,4- \\
\text { Diene }\end{array}$ & $\begin{array}{c}\mathrm{C}_{1} \ldots \mathrm{C}_{5} \\
(\AA)\end{array}$ & $\begin{array}{c}\mathrm{C}_{2} \ldots \mathrm{C}_{4} \\
(\AA)\end{array}$ & $\Phi_{1 i}$ & $\Phi_{1 o}$ & $\Phi_{2 i}$ & $\Phi_{2 o}$ & $\Delta E_{\text {strain }}$ \\
\hline$\underline{12}$ & $3 \cdot 85$ & $2 \cdot 50$ & 35 & -143 & -30 & 148 & 38.0 \\
\hline 13 & $3 \cdot 54$ & $2 \cdot 40$ & 43 & -137 & -42 & 135 & $37 \cdot 4$ \\
\hline$\underline{14}$ & 3.57 & 2.49 & 38 & -142 & -37 & 141 & 46.0 \\
\hline$\overline{15}$ & $3 \cdot 53$ & $2 \cdot 48$ & 36 & -143 & -40 & 138 & 46.0 \\
\hline$\overline{16}$ & 4.09 & $2 \cdot 54$ & 40 & -139 & -40 & 138 & 342 \\
\hline 17 & 4.07 & $2 \cdot 38$ & 48 & -131 & -47 & 131 & $26 \cdot 0$ \\
\hline$\underline{18}$ & $4 \cdot 40$ & $2 \cdot 44$ & 44 & -135 & -43 & 137 & $31 \cdot 3$ \\
\hline 19 & 4.59 & 2.48 & 38 & -140 & -37 & 143 & $28 \cdot 1$ \\
\hline 20 & $4 \cdot 37$ & $2 \cdot 44$ & 43 & -135 & -44 & 135 & 36.0 \\
\hline 21 & $4 \cdot 71$ & $2 \cdot 30$ & 44 & -136 & -44 & 135 & $45 \cdot 6$ \\
\hline
\end{tabular}

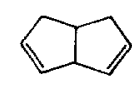

$\underline{12}$

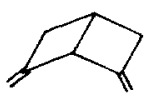

$\underline{16}$

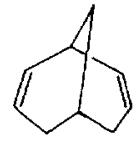

$\underline{13}$

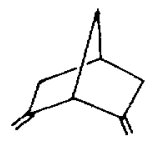

$\underline{17}$

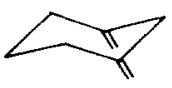

$\underline{20}$

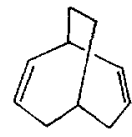

$\underline{14}$

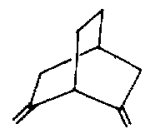

18

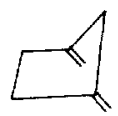

$\underline{21}$

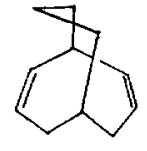

$\underline{15}$<smiles>C1CC2CCC1CC2</smiles>

19 


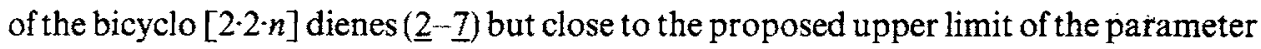
for observable HDA reactivity. Interestingly, the calculated tilt angles for the series are consistently more favourable compared to the series of bicyclo $[2 \cdot 2 \cdot n]$ dienes. However, the strain energy factor is calculated to be more unfavourable in the bicyclo [3.3.n]

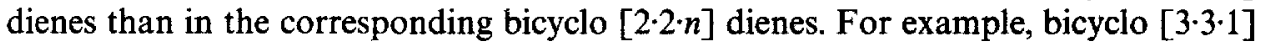
nona-2,7-diene ( $\underline{13})$ is computed to have a strain energy increase of $37.4 \mathrm{kcal} / \mathrm{mol}$ (table 4), while the value for norbornadiene is only $21 \mathrm{kcal} / \mathrm{mol}$ (table 1). The increase in strain energy is much higher in dienes with larger methylene bridges.

On the basis of the above results, it would be worthwhile to examine the homoDiels-Alder reactivity of bicyclo[3.3.1] nona-2,7-diene (13). If the molecule does undergo the reaction, the proposed empirical criteria would be validated.

The terminal $\mathrm{C}_{1} . . \mathrm{C}_{5}$ distances in the next series of 1,4-dienes $\underline{16}-\underline{21}$ considered in this study are found to be higher than in all the previously examined systems, being consistently more than $4.0 \AA$ (table 4). However, the tilt angles are quite favourable in the exo-methylene derivatives compared to that of the bicyclic dienes 2-6 and the bicyclo [3.3.n] dienes $16-21$. Further, the strain energy increases on HDA addition are also found to be relatively small. A particularly interesting case is the diene 2,6dimethylidene-bicyclo[2.2.1] heptane (17) for which the increase in strain energy is only $26 \mathrm{kcal} / \mathrm{mol}$. Although the $\mathrm{C}_{1} . . \mathrm{C}_{5}$ distance is $4.07 \AA$ in this system, on the basis of favourable tilt angles $\left(48^{\circ},-131^{\circ}\right.$ at terminal and $-47^{\circ}, 131^{\circ}$ at internal carbon atoms) and the relatively modest increase in strain energy, it is also a worthy candidate for experimental examination as a HDA substrate. If $\underline{17}$ is reactive, the limit for the $C_{1} . . C_{5}$ distance of the 1,4-diene for HDA reaction needs to be extended. Also, a subsequent study of $\underline{18}-\underline{20}$ may be attempted. In these dienes, the tilt angles and strain energy increases are within the limits proposed above. The only unfavourable feature is calculated to be the distance between the terminal carbon atoms. Hence, the reactivity of these systems would establish the upper bound for the geometric criterion for the HDA reaction.

\section{Conclusions}

Computed geometries and strain energies of several 1,4-dienes with known HDA reactivity suggest possible factors which may be crucial. Based on available experimental information, a few essential requirements for HDA reactivity have been proposed. The reactive dienes have a C1..C5 separation of less than $3.5 \AA$, tilt of $\pi$ lobes of over $30^{\circ}$ and modest strain energy increase (less than $40 \mathrm{kcal} / \mathrm{mol}$ ) for cycloadduct formation. Additional substrates for experimental study are suggested to establish the limits more precisely and to enhance the scope of the HDA reaction. These proposals may be of use for a quick appraisal of potential HDA reactivity of a non-conjugated diene.

It would be of interest to evaluate the reliability of the criteria derived from molecular mechanics calculations by determining the geometries and energies of transition states for representative substrates through quantitative MO procedures. The results of these studies, currently underway, will be reported shortly.

\section{Acknowledgement}

AP thanks the Council of Scientific and Industrial Research, New Delhi for a fellowship. 


\section{References}

Allinger N L 1977 J. Am. Chem. Soc. 998127

Birch A J, Hinde A L and Radom L 1981 J. Am. Chem. Soc. 103284

Blomquist A T and Meinwald Y C 1959 J. Am. Chem. Soc. 81667

Cookson R C and Dance J 1962 Tetrahedron Lett. 879

Cookson R C, Dance J and Hudec J 1964 Tetrahedron Lett. 5416

Cristol S J, Allred E L and Wetzel D L 1962 J. Org. Chem. 274058

Fickes G N and Metz T E 1978 J. Org. Chem. 434057

Grant F W, Gleason R W and Bushweller C H 1965 J. Org. Chem. 30290

Hall H K 1960 J. Org. Chem. 2542

Huebner C F, Donoghue E, Dorfman L, Stuber E A, Danieli N and Wenkert E 1966 Tetrahedron Lett. 1185

Iwamura H, Tanabe Y and Kobayashi H 1976 Tetrahedron Lett. 1987

Jenner G and Papadopoulos M 1982 Tetrahedron Lett. 234333

Kobuke Y, Sugimoto T, Furukawa J and Fueno T 1972 J. Am. Chem. Soc. 943633

Krespan C G, McKusick B C and Cairns T L 1961 J. Am. Chem. Soc. 833428

Lautens $M$ and Edwards L G 1991 J. Org. Chem. 563761

Moriarty R M 1963 J. Org. Chem. 282385

Sasaki T, Eguchi S, Sugimoto M and Hibi F 1972 J. Org. Chem. 372317

Schrauzer G N and Glockner P 1964 Chem. Ber. 972451

Tabushi I, Yamamura K, Yoshida Z and Togashi A 1975 Bull. Chem. Soc. Jpn. 482922

Tufariello J J, Mich T F and Miller P S 1966 Tetrahedron Lett. 2293

Ullman E F 1958 Chem. Ind. (London) 1173

Williams J K and Benson R E $1962 \mathrm{~J}$. Am. Chem. Soc. 841257

Yamaguchi R, Ban M and Kawanisi M 1984a J. Chem. Soc., Chem. Commun. 826

Yamaguchi R, Ban M, Kawanisi M, Osawa E, Jaime C, Buda A B and Katsumata S 1984b J. Am. Chem. Soc. 1061512

Zimmerman H E and Swenton J S 1964 J. Am. Chem. Soc. 861434 